\title{
Candidate gene association analyses for ketosis resistance in Holsteins
}

\author{
V. Kroezen, ${ }^{*}$ F. S. Schenkel, ${ }^{*}$ F. Miglior, ${ }^{*}+$ C. F. Baes, ${ }^{*}$ and E. J. Squires ${ }^{* 1}$ \\ ${ }^{*}$ Centre for Genetic Improvement of Livestock, Department of Animal Biosciences, University of Guelph, ON, Canada, N1G 2W1 \\ †Canadian Dairy Network, Guelph, ON, Canada, N1K 1E5
}

\begin{abstract}
High-yielding dairy cattle are susceptible to ketosis, a metabolic disease that negatively affects the health, fertility, and milk production of the cow. Interest in breeding for more robust dairy cattle with improved resistance to disease is global; however, genetic evaluations for ketosis would benefit from the additional information provided by genetic markers. Candidate genes that are proposed to have a biological role in the pathogenesis of ketosis were investigated in silico and a custom panel of 998 putative single nucleotide polymorphism (SNP) markers was developed. The objective of this study was to test the associations of these new markers with deregressed estimated breeding values (EBV) for ketosis. A sample of 653 Canadian Holstein cows that had been previously genotyped with a medium-density SNP chip were regenotyped with the custom panel. The EBV for ketosis in first and later lactations were obtained for each animal and deregressed for use as pseudo-phenotypes for association analyses. Results of the mixed inheritance model for single SNP association analyses suggested 15 markers in 6 unique candidate genes were associated with the studied trait. Genes encoding proteins involved in metabolic processes, including the synthesis and degradation of fatty acids and ketone bodies, gluconeogenesis, lipid mobilization, and the citric acid cycle, were identified to contain SNP associated with ketosis resistance. This work confirmed the presence of previously described quantitative trait loci for dairy cattle, suggested novel markers for ketosis-resistance, and provided insight into the underlying biology of this disease.
\end{abstract}

Key words: candidate gene, ketosis, single nucleotide polymorphisms

\section{INTRODUCTION}

All modern dairy cattle that have been selected for a high level of milk production undergo metabolic stress

Received June 21, 2017.

Accepted February 14, 2018.

${ }^{1}$ Corresponding author: jsquires@uoguelph.ca during the periparturient period. As the cow's demand for nutrients greatly increases after calving to sustain lactogenesis, she must alter energy metabolism in the liver and peripheral tissues (Bauman and Currie, 1980; Drackley et al., 2005). In response to negative energy balance, ruminants mobilize body stores of protein and fat to oxidize as body fuel so that carbohydrates may be conserved to support milk synthesis (Tamminga et al., 1997). Decreasing glucose and insulin concentrations mediate the major metabolic changes needed to stabilize blood glucose, which include increased rate of gluconeogenesis, reduced lipogenesis and increased release of nonesterified fatty acids from adipose, increased uptake and metabolism of fatty acids in the mitochondria of hepatocytes, and increased ketogenesis (Herdt, 2000). The fatty acids and ketone bodies are used as an alternate fuel source in the heart, kidney, skeletal muscle, and mammary gland to further conserve glucose and restore energy balance (Heitmann et al., 1987; Schäff et al., 2013); however, cows that do not make the necessary metabolic adaptations are susceptible to hyperketonemia. Differences in metabolite profiles, nutrient partitioning and hepatic regulation of metabolism of ketotic and nonketotic cows have been described, although the results of these studies have been inconclusive in explaining why some high-yielding cows develop ketosis whereas most do not (Loor et al., 2007; Moyes et al., 2013; van Dorland et al., 2014).

Interest in breeding more robust dairy cattle with improved resistance to disease is global (Miglior et al., 2005; Kargo et al., 2014; Parker Gaddis et al., 2014; Koeck et al., 2015). In 2016, Zoetis Genetics (Kalamazoo, MI) released a commercial genetic evaluation system for dairy wellness traits (Vukasinovic et al., 2017). The Canadian Dairy Network (Guelph, ON), the dairy genetic evaluation unit in Canada, has released a metabolic disease-resistance index (Koeck et al., 2014; Jamrozik et al., 2016a,b; Miglior et al., 2017). Ketosis is a multifactorial disease that is most likely influenced by multiple loci. Genetic evaluations of ketosis have produced low estimates of heritability $(0.02-0.06)$ that limits the selection of cattle for ketosis resistance; milk $\mathrm{BHB}$, an indicator trait for ketosis, has a relatively higher heritability (0.14-0.28; Zwald et al., 2004; van 
der Drift et al., 2012; Koeck et al., 2012; Koeck et al., 2014).

Investigation of candidate genes for ketosis and related traits could contribute to our understanding of the genetic architecture of this trait. Candidate gene association analyses, which are often limited by scope, are commonly conducted by estimating the association of polymorphisms in a few genes expressed in key tissue sites with the incidence of a disease. The construction of a custom array of markers for candidate genes specific to the trait of interest would allow for the investigation of many key genes simultaneously, as well as identifying probable quantitative trait nucleotides with biological significance. The objective of our study was to test the association of a custom panel of candidate gene SNP markers with a ketosis-resistance trait.

\section{MATERIALS AND METHODS}

\section{Candidate Gene Markers}

A custom genetic marker panel of SNP was developed by investigating candidate genes related to ketosis. Candidate genes were proposed based on their biological role in metabolic pathways related to the development of ketosis. Enzymes and regulatory factors known to be involved in gluconeogenesis, fatty acid synthesis and degradation, the citric acid/tricarboxylic acid cycle, and ketone synthesis and degradation were recognized by searching the species-specific Kyoto Encyclopedia of Genes and Genomes (www.genome.jp/ kegg) pathway database. Candidate genes for ketosis that have been suggested in the scientific literature were also considered; those studies have identified key genes by comparing the transcriptome, proteome and metabolome of transitioning cows (Loor et al., 2005, 2007; van Dorland et al., 2009, 2014; Li et al., 2012; Moyes et al., 2013; Akbar et al., 2015a,b). Additionally, genes suggested by studies that have mapped QTL to important candidate genes for metabolic traits were also chosen (Clempson et al., 2012; Buitenhuis et al., 2013; Tetens et al., 2013). More than 100 genes were investigated in silico to categorize reported SNP from dbSNP (www.ncbi.nlm.nih.gov/snp) and to detect novel SNP. For each gene, the species-specific GenBank, UniGene, and dbSNP databases that are maintained by the National Center for Biotechnology Information (www.ncbi.nlm.nih.gov) were mined for gene reference sequences, expressed sequence tags, and SNP data, respectively. The downloaded sequence and SNP data for each gene was compiled and aligned by the variant calling software Sequencher v. 4.9 (Gene Codes Corp., Ann Arbor, MI), using the UMD 3.1.1 (www .bovinegenome.org) for Bos taurus. The SNP located in coding regions were prioritized for inclusion based on their predicted effect on gene products; the Sorting Intolerant From Tolerant (SIFT; www.sift.jcvi.org) algorithm was used to determine if an allele substitution would change the encoded AA, and if this change would alter protein function (Sim et al., 2012). A total of 998 SNP were classified and incorporated onto an Illumina (Illumina Inc., San Diego, CA) 8K microarray to create a custom panel of markers. These putative SNP are located in 120 candidate genes spanning 28 chromosomes. With the exception of 14 SNP, the panel contains markers that were not previously included on a commercial bovine SNP chip. The SNP are a combination of novel and reported SNP that are located within or near candidate genes related to ketosis. The position of the 998 markers included on the panel are presented in Supplemental Table S1 (https://doi.org/ 10.3168/jds.2017-13374).

\section{Animals and Data}

Genomic DNA samples were obtained through coordination with previous Canadian Dairy Network (Guelph, ON) initiatives. All samples were from cows that had previously been genotyped with the BovineSNP50 BeadChip (Illumina Inc.), and these 50K genotypes were also provided by Canadian Dairy Network. A sample of 653 Canadian Holstein cows were regenotyped with the low-density array containing the 998 putative ketosis markers. Quality control removed animals with genotyping call rate less than $90 \%$ and SNP with minor allele frequency less than $1 \%$ and excess of heterozygosity greater than $15 \%$. A pedigree file was derived for these cows, consisting of 24,260 individuals traced back 7 generations.

The cows came from 5 large herds of at least 100 recorded cows located within Quebec and Ontario with an annual ketosis disease-reporting frequency greater than $1 \%$ for each year of recording to ensure herds with inconsistent recording were avoided. Selective genotyping was implemented to increase the frequency of recorded cases of clinical ketosis in the small sample and consequently increase the power of the association analyses. Therefore, cow selection for genotyping was not randomized, but based roughly on creating a sample with close to equal numbers of cases and controls for ketosis based on the producer-recorded health records (322 cases and 331 controls). A case animal was defined as a cow with at least 1 reported case of ketosis within the first $100 \mathrm{~d}$ postpartum, which is the risk period for ketosis, and a control was defined as a cow with no reported case of ketosis in any period of her recorded 
lactations. Health data from April 2007 to December 2015 were obtained from Canadian Dairy Network and matched to the genotyped cows. Only records from the first 5 lactations were considered; 1 record from lactation 2 to 5 was randomly selected for cows with more than 1 later-lactation record. Each cow with a ketosis record also had a milk BHB record predicted from first test-day (5-40 DIM) milk samples that have been analyzed by a mid-infrared spectrometer (MilkoScan FT+, Foss, Hillerød, Denmark). Random selection of 1 later-lactation ketosis and milk BHB record was based on the fact that the incidence of ketosis in subsequent parities are strongly correlated (0.77-0.99; Koeck et al., 2014). Disease records are reported by producers as a binary trait; a score of 0 being no reported case, and a score of 1 representing at least 1 case of ketosis reported. A case of ketosis was only considered if it was reported within the first $100 \mathrm{~d}$ postpartum, which is the risk period for ketosis. After this data edit, there were 195 first-lactation records and 445 later-lactation records for the genotyped cows. Although cows were selected for genotyping based on their health records, the disease frequencies for first- and later-lactation records were less than $50 \%$ because of the data editing steps taken (Table 1).

In Canada, producer-recorded disease data and milk test-day records provide reliable sources of information on health traits for dairy cattle, which are used for genetic evaluation (Neuenschwander et al., 2012; Koeck et al., 2015; Jamrozik et al., 2016a,b; Miglior et al., 2017). Genetic evaluations for metabolic disease traits were available in Canada as of December 2016 (Miglior et al., 2017). The calculation of EBV includes added information from the performance of relatives for a trait of interest and correlated traits, which can be a more reliable measure than the record of an animal from a single lactation. Deregressed EBV for ketosis were used as pseudo-phenotypes for the analysis. The EBV for primiparous and multiparous cows were analyzed as separate traits, resulting in $2 \mathrm{EBV}$ for each animal. Previous studies propose that cows respond to negative energy balance differently in their first lactation compared with later lactations, so that for genetic analysis these traits are considered to be separate, but correlated traits (Chapinal et al., 2012; Koeck et al., 2015; Jamrozik et al., 2016a,b).

Official EBV and corresponding reliabilities for ketosis were obtained from Canadian Dairy Network and matched to the genotyped cows and their sire and dam. The EBV were calculated individually by Canadian Dairy Network as described by Jamrozik et al. (2016a,b). The EBV were deregressed by removing the parent average and using EBV reliabilities following
Table 1. Summary statistics for phenotypic records for genotyped cows

\begin{tabular}{lcc}
\hline & \multicolumn{2}{c}{ Lactation group } \\
\cline { 2 - 3 } Phenotype $^{1}$ & $\begin{array}{c}\text { First lactation } \\
(\mathrm{n}=195)\end{array}$ & $\begin{array}{c}\text { Later lactations } \\
(\mathrm{n}=445)\end{array}$ \\
\hline Ketosis & 35.9 & 23.2 \\
Milk BHB & 0.094 & 0.115 \\
& $(0.0535)$ & $(0.0626)$ \\
\hline
\end{tabular}

${ }^{1}$ The frequency of clinical disease $(\%)$ is shown for ketosis and the mean values $(\mathrm{mmol} / \mathrm{L})$ for milk BHB with the associated standard deviation shown in brackets below.

methods presented by Garrick et al. (2009). As EBV for metabolic traits were not available for all sires and dams, deregressed EBV were calculated for 322 and 324 cows for first- and later-lactation ketosis, respectively. Animals with deregressed EBV with calculated reliability less than $5 \%$ were also removed from the analysis. There were 3 and 23 animals removed for the analysis of first lactation and later lactation deregressed EBV for ketosis, respectively.

\section{Association Analyses}

Associations between candidate gene SNP genotypes and deregressed EBV were investigated using SNP1101 (Sargolzaei, 2014). The univariate single SNP mixed model was fit as

$$
\mathrm{y}_{\mathrm{i}}=\mu+b \mathrm{SNP}+\mathrm{a}_{\mathrm{i}}+\mathrm{e}_{\mathrm{i}}
$$

where $y_{i}$ is the phenotype of the ith individual; $\mu$ is the overall mean; SNP is the genotype of an SNP in the individual, which has been recoded as 0,1 , and 2 , for genotype $\mathrm{AA}, \mathrm{AB}$, and $\mathrm{BB}$, respectively; $b$ is the regression coefficient of $y_{i}$ on SNP genotype, which is the allele substitution effect; $a_{i}$ is the random additive genetic (polygenic) effect of the ith individual with $\mathrm{a}_{\mathrm{i}} \sim N\left(0, \mathbf{A} \sigma_{\mathrm{a}}^{2}\right)$, where $\mathbf{A}$ is the additive genetic relationship matrix among individuals and $\sigma_{\mathrm{a}}^{2}$ is the additive genetic variance; $e_{i}$ is the random residual effect of the ith individual's record with $\mathrm{e}_{\mathrm{i}} \sim N\left(0, \mathbf{I} \sigma_{\mathrm{e}}^{2}\right)$, where $\mathbf{I}$ is an identity matrix and $\sigma_{\mathrm{e}}^{2}$ is the error variance. The expectations are $\mathrm{E}\left(\mathrm{a}_{\mathrm{i}}\right)=0$ and $\mathrm{E}\left(\mathrm{e}_{\mathrm{i}}\right)=0$.

False discovery rate (FDR; Benjamini and Hochberg, 1995) at the chromosome level was used to correct for multiple testing. The FDR correction was applied at the less-stringent chromosome level instead of at the genome level because of the unequal distribution of SNP on the custom marker panel. These markers are highly concentrated in and around candidate genes and are not 
distributed evenly across the genome. A large number of the tests are correlated due to linkage disequilibrium between markers in the same candidate gene; therefore, correcting for all tests would be too stringent and lead to false negatives. The FDR is the expected proportion of discoveries $\left(q^{*}\right)$ that are expected to be false. A FDR threshold (q-value) less than $5 \%$ for a SNP was the threshold for significant association with the traits, whereas a $q$-value less than $10 \%$ was considered a trend. A less-conservative threshold of $10 \%$ was chosen based on the biological a priori information of the candidate gene markers.

\section{RESULTS AND DISCUSSION}

\section{Marker Panel}

A sample of 653 Holstein cows from Ontario and Quebec were genotyped with the custom panel of candidate gene SNP. Unlike a typical candidate gene association analysis, which may focus on identifying SNP in a limited number of genes by sampling and sequencing cows with extreme phenotypes, over 100 genes were represented on the custom marker panel. After removing SNP that did not meet quality control criteria, 336 SNP were considered for the association analyses; just $34 \%$ of the SNP on the panel were polymorphic (minor allele frequency $>0.01$ ). The range of minor allele frequency was between 0.012 and 0.493 . These SNP are found within or near 94 unique candidate genes and located on all autosomes except BTA12 and BTA28; BTA3 contained the highest number (40) of SNP. The SNP are a combination of novel and reported SNP that are located within or near candidate genes related to ketosis. Despite the challenges of identifying SNP in silico, development of the marker panel allowed for the analysis of several hundred new markers for ketosis and is a tool that may be used in the future to study other related metabolic traits.

\section{Genome-Wide Association Study}

Unlike a typical genome-wide association study, the SNP we used are not anonymous, common markers, but SNP found in genes proposed to influence metabolic adaptation during the transition period. Markers that are included on commercial SNP chips were not chosen in reference to any particular trait; these markers depend on dense coverage of the entire genome in linkage with a QTL (Brøndum et al., 2015). Whereas marker density has increased over the past decade and whole genomes are being readily sequenced, the argument for including SNP located in candidate genes remains valid. The inclusion of trait-specific markers on marker panels has been shown to improve the accuracy of genomic prediction for traits in dairy cattle (Brøndum et al., 2015; Raven et al., 2016). VanRaden et al. (2011) determined by simulation that gains in reliability by increasing marker density is limited. Raven et al. (2016) reported an increase in accuracy of 7 to $9 \%$ for the genomic prediction of milk fat and protein, respectively, when markers near candidate genes were used compared with a panel of more than $600 \mathrm{~K}$ common SNP. As more QTL are reported for functional traits, the reliability of health traits may be improved greatly by adding candidate gene markers to SNP panels. A natural next step, once more animals can be genotyped, will be to test the improvement in genomic prediction with or without the addition of the ketosis-specific markers.

A case-control design for selecting cows for genotyping was implemented to increase the power to detect associations. Calculation of power in association analyses is not trivial and requires several assumptions. The PGA (Power for Genetic Association Analyses) software (Menashe et al., 2008) was used to compare the expected power of case-control analysis to the power using general population analysis for an additive SNP locus, using the sample sizes in the current study to provide an indication of how much the power would be increased by using a case-control design. The assumptions for the power analysis included an additive SNP locus, marker allele frequencies of 0.25 and 0.30 for the causative mutation and marker, respectively, and a level of linkage disequilibrium between causative and marker loci of 0.80 (allelic $\mathrm{r}^{2}$ ). Sample sizes were consistent with the number of animals used in the current study. The disease frequencies of our study were applied for the case-control analysis and the estimated incidence of ketosis in dairy herds in Canada (4.5\%; Koeck et al., 2012) was applied for the general population analysis. For first lactation, the case-control selection analysis was expected to have a power of $68 \%$, whereas for later lactations it was $81 \%$. For the general population, the power would be 2 and $4 \%$ for the same number of control animals as in first and later lactations, respectively. Therefore, the use of case-control design drastically increased power, making the sample sizes available for first and later lactations reasonable in terms of expected power. In addition, the analyses performed in the current study used a more complete mixed inheritance model by including the SNP effect in addition to the additive polygenic genetic effect of the animal and fitting the additive genetic relationships among individuals, which should increase power and minimize possible spurious associations due to family stratification. 
The quantile-quantile plots for the marker-trait association analysis for deregressed ketosis EBV in first and later parities are presented in Figure 1. For the analyses of ketosis EBV, the range of the inflation factor $\left(\lambda_{\text {mean }}\right)$ was between 0.958 and 1.069, thus not indicating strong deflation or inflation of the observed distribution of $P$ values. An acceptable number of extreme $P$-values are apparent in the plots for each analysis.

The association analyses of deregressed EBV for ketosis identified 5 SNP that reached chromosome-level significance $(\mathrm{FDR}<0.05)$ and 10 that were suggestive (FDR <0.10; Table 2). The SNP were identified within genes involved in cell signaling, fibronectin 1 (FN1); fatty acid activation and oxidation, acyl-CoA synthetase long-chain family member 1 (ACSL1), carnitine palmitoyltransferase $1 \mathrm{~A}(C P T 1 A)$, isocitrate dehydrogenase $3(\mathrm{NAD}+) \beta(I D H 3 B)$; gluconeogenesis, pyruvate carboxylase $(P C)$; and ketogenesis, 3-hydroxy3-methylglutaryl-CoA synthase 2 (HMGCS2). No overlap between the SNP detected using first- and laterlactation records was observed. Variable results are likely attributable to the distribution of genotypes in the small subsets. One might speculate that this finding reflects the fact that the genetic correlation between clinical ketosis in first and later lactations is only moderate (0.66; Jamrozik et al., 2016a). The increased risk of developing ketosis in later lactations has been well documented, but the root of the metabolic variances between heifers and cows has not been established (Berge and Vertenten, 2014; Vanholder et al., 2015).

\section{Candidate Genes for Ketosis}

Several identified genes encode hepatic enzymes that are critical to the control of energy metabolism. The expression of ACSL1, CPT1A, and PC have been shown to be upregulated at parturition in correlation with high levels of fatty acids and BHB (Graber et al., 2010; Weber et al., 2013). Both ACSL1 and CPT1A encode proteins that control the rate of activated fatty acids entering the mitochondria for oxidation; functional mutations within either gene may influence the fate of fatty acids that accumulate in the liver when the cow is in negative energy balance. One SNP in ACSL1 was found to show a trend (FDR <0.1) of association, whereas 4 SNP located within CPT1A were associated with first-lactation EBV (FDR <0.05). The SNP detected within CPT1A are located within a narrow range $(700 \mathrm{bp})$ of the $3^{\prime}$ untranslated region (UTR) of the gene and show perfect linkage disequilibrium. Further work must be done to determine whether one of these SNP is the causative mutation or if they show linkage with a SNP that was not included on the cus- tom marker panel. Another $12 \mathrm{SNP}$ within both the 5'UTR and coding region of CPT1A were found to be segregating in the sample but did not show association with the trait.

A SNP within the gene $P C$ was also found to be associated with first-lactation ketosis EBV (FDR <0.05); $P C$ encodes a gluconeogenic enzyme that provides substrates for both the citric acid cycle and gluconeogenesis. These are critical pathways that affect production of glucose and energy balance in the transitioning cow (Reynolds et al., 2003). Further, $P C$ promoter 1 has been shown to be regulated in part by fatty acids in an adaptive response to feed restriction and negative energy balance (White et al., 2011). No SNP on the marker panel were located within the 3 distinct promoters of the gene, and this may be an area to focus on in future studies. The SNP found to be associated with ketosis EBV in our study is a nonsynonymous mutation $(\mathrm{I} \rightarrow \mathrm{V})$, although this change is predicted to have no effect on protein function (Sim et al., 2012).

Gene HMGCS2 is a rate-limiting enzyme for the synthesis of ketone bodies (Voet et al., 2002). Although studies have shown that the expression level of HMGCS2 is not altered by metabolic status of dairy cows, 6 SNP were suggested to be associated with deregressed EBV for ketosis in later lactations in the current study (Loor et al., 2007; van Dorland et al., 2009, 2014; Graber et al., 2010). Three of the SNP in $H M G C S 2$ are synonymous mutations in the coding region and 3 are located in the $3^{\prime} U T R$. Being in the untranslated region of the gene makes it difficult to interpret if changes to protein translation or function may be a consequence of this mutation; although, SNP within $3^{\prime}$ UTR should not be discounted because of this and have been shown to contribute to major phenotypic changes (Clop et al., 2006). Notably, 2 additional nonsynonymous SNP within HMGCS2 were included on the marker panel; however, one did not reach quality control thresholds and the other was not associated with the trait studied. Functional characterization of these SNP would be valuable to determine if these SNP affect gene or protein expression and, ultimately, the adaptive ability of the cow.

The only other gene identified in the analysis of later-lactation deregressed ketosis EBV was FN1, which contained 2 suggestive SNP. Fibronectin 1 is an extracellular matrix protein that has been linked to many signaling pathways and interactions (Voet et al., 2002; Loor et al., 2007). Although the mechanistic relationship with ketosis is not yet clear, FN1 has been shown to be differentially expressed in the liver tissue of ketotic cows and a QTL for the milk metabolite malonate has been mapped to this gene (Loor et al., 2007; 
A Uniform QQ plot of $-\log _{10}(P)$ for KET

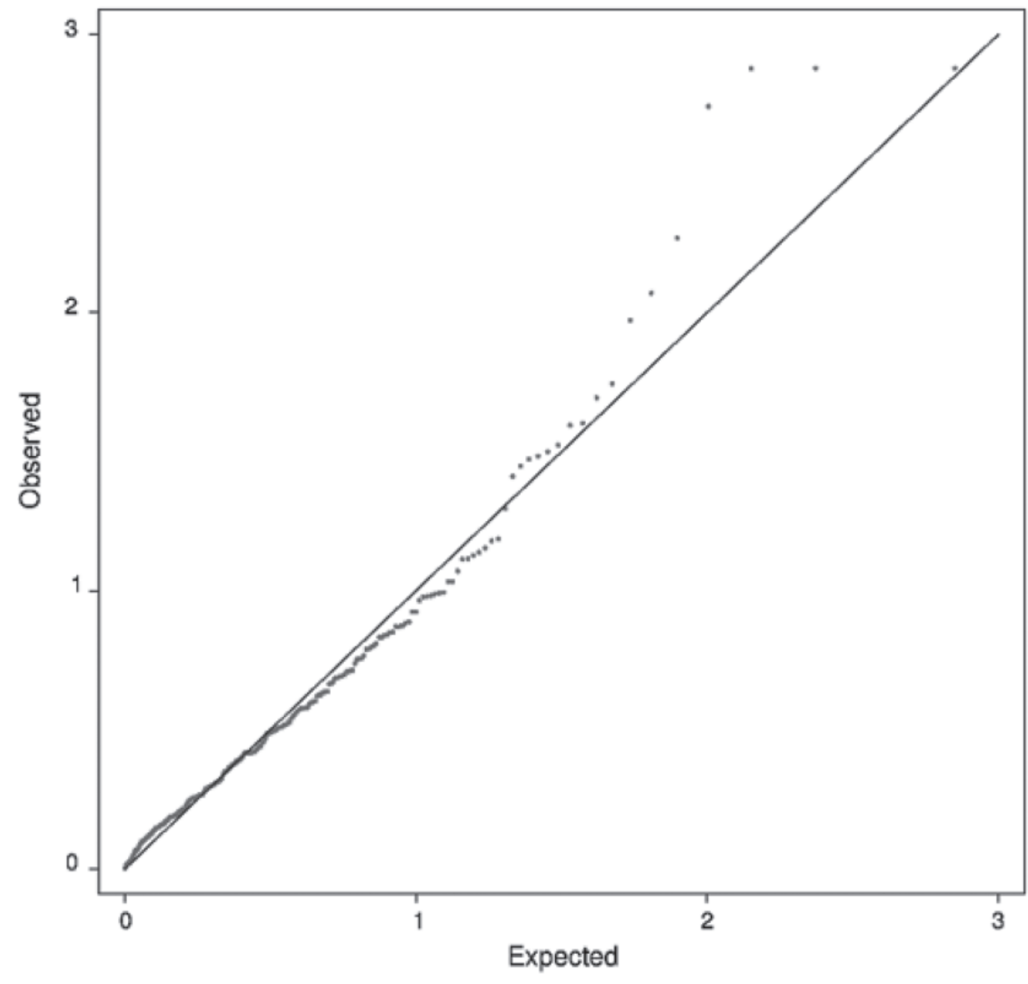

B Uniform QQ plot of $-\log _{10}(P)$ for KET

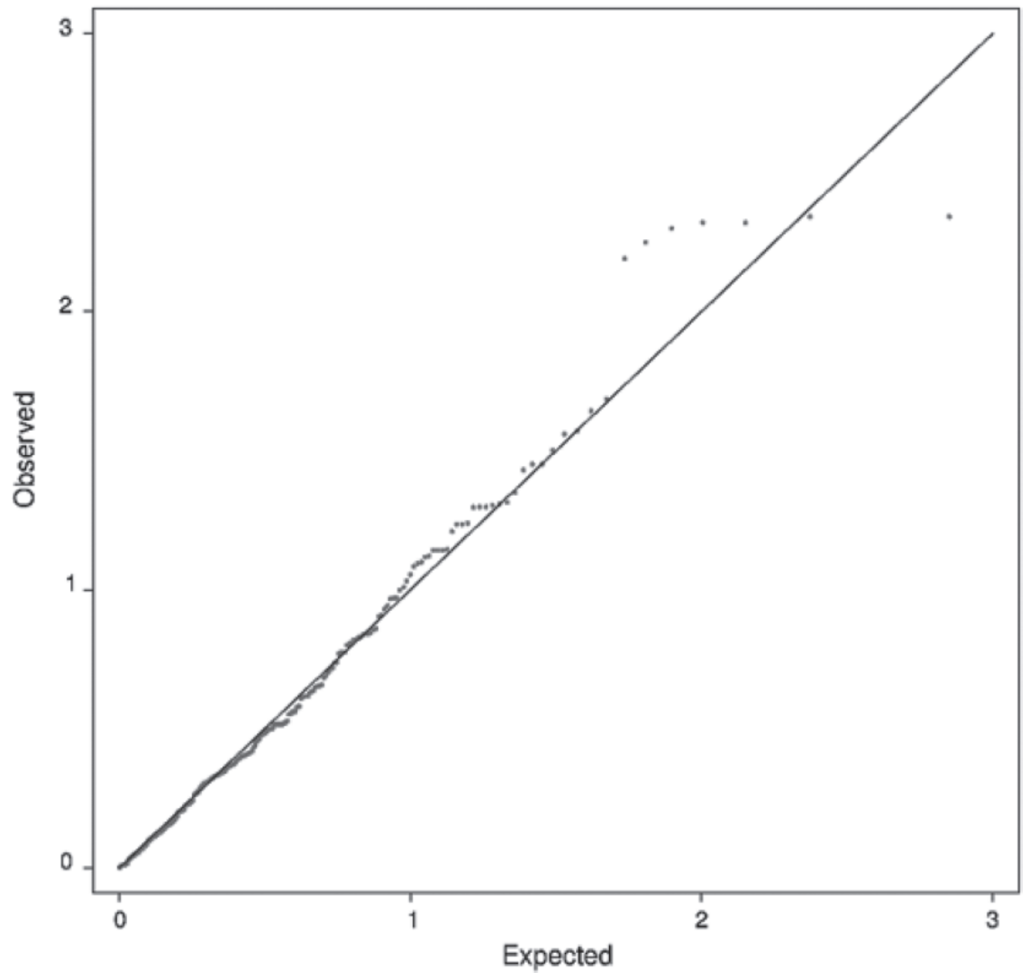

Figure 1. Quantile-quantile (QQ) plots of the expected and observed $P$-values for the marker-trait associations studies for (A) first-parity deregressed EBV for ketosis (mean inflation factor $\lambda$ equal to 1.069), and (B) parity 2 to 5 deregressed EBV for ketosis (KET; mean inflation factor $\lambda$ equal to 0.958$)$. 
Table 2. SNP associated with first or later (lactation 2 to 5) parity ketosis deregressed EBV (breed average $=100$ )

\begin{tabular}{|c|c|c|c|c|c|c|c|}
\hline $\mathrm{SNP}_{\mathrm{ID}}{ }^{1}$ & BTA & Gene & Allele $^{2}$ & Freq $^{3}$ & Effect $^{4}$ & $P$-value ${ }^{5}$ & $\mathrm{Con}^{6}$ \\
\hline \multicolumn{8}{|l|}{ First lactation $(\mathrm{n}=319)$} \\
\hline rs208796014 & 13 & IDHзВ & G & 0.123 & 12.6 & $0.011 \dagger$ & Synonymous \\
\hline rs378674931 & 27 & ACSL1 & A & 0.894 & 15.4 & $0.008 \dagger$ & 3' UTR \\
\hline rs42194371 & 29 & CPT1A & G & 0.305 & 11.7 & $0.001^{*}$ & $3^{\prime} \mathrm{UTR}$ \\
\hline rs42194370 & 29 & CPT1A & A & 0.305 & 11.7 & $0.001^{*}$ & $3^{\prime} \mathrm{UTR}$ \\
\hline c. $2982 \mathrm{G}>$ A XM_005227376 & 29 & CPT1A & G & 0.305 & 11.7 & $0.001^{*}$ & $3^{\prime} \mathrm{UTR}$ \\
\hline \multicolumn{8}{|l|}{ Later lactations $(\mathrm{n}=301)$} \\
\hline c.5424C>T NM_001163778 & 2 & FN1 & $\mathrm{T}$ & 0.532 & 13.3 & $0.022 \dagger$ & $\mathrm{R} \rightarrow \mathrm{T}$ \\
\hline rs109315364 & 2 & FN1 & A & 0.733 & 19.2 & $0.006 \dagger$ & Synonymous \\
\hline rs109948517 & 3 & $H M G C S 2$ & G & 0.767 & 18.4 & $0.004 \dagger$ & Synonymous \\
\hline rs109226505 & 3 & HMGCS2 & $\mathrm{C}$ & 0.774 & 17.5 & $0.006 \dagger$ & Synonymous \\
\hline rs110481138 & 3 & $H M G C S 2$ & $\mathrm{C}$ & 0.768 & 18.3 & $0.005 \dagger$ & Synonymous \\
\hline rs109648007 & 3 & HMGCS2 & $\mathrm{C}$ & 0.770 & 18.6 & $0.005 \dagger$ & $3^{\prime} \mathrm{UTR}$ \\
\hline rs134403515 & 3 & $H M G C S 2$ & $\mathrm{C}$ & 0.770 & 18.6 & $0.005 \dagger$ & 3' UTR \\
\hline
\end{tabular}

${ }^{1}$ The SNP identifier is based on either the dbSNP (www.ncbi.nlm.nih.gov/snp) reference SNP cluster ID number (rs\#) or the DNA sequence change and associated GenBank (www.ncbi.nlm.nih.gov) cDNA reference sequence for SNP that are not classified in dbSNP. Note that the version number of the reference sequence may be updated often.

${ }^{2}$ The favorable allele.

${ }^{3}$ The frequency of the favorable allele.

${ }^{4}$ The estimated allele substitution effect. These estimates are expected to be overestimated due to the selective genotyping used to increase the power of the association analysis.

${ }^{5}$ The significance level is reported as * for chromosome-wise false discovery rate less than 0.05 and $\dagger$ less than 0.10.

${ }^{6}$ The consequence of the mutation [synonymous or relevant AA substitution or location in a $3^{\prime}$ of $5^{\prime}$ untranslated region (UTR) of the gene].

Buitenhuis et al., 2013). The consequence of the nonsynonymous mutation at c.5424C $>\mathrm{T}$ is the translation of a threonine residue instead of arginine. Threonine is a neutral, polar AA, whereas arginine is basic; the substitution is predicted to not be tolerated and result in changes to the encoded protein's function based on SIFT scoring (Sim et al., 2012). Although the effect of these SNP on the phenotypes is not easily explained, the associations reported for ketosis deregressed EBV provide additional evidence of the relationship between FN1 and ketosis that should be studied further.

A notable SNP within the gene enoyl-CoA hydratase and 3-hydroxyacetyl-CoA dehydrogenase (EHHADH) that did not reach the threshold for a statistical trend (FDR <0.20) was identified to be of interest due to its proximity to a previously described QTL and the large estimated allele effect in the current study. This SNP supports the evidence of a QTL for milk fat traits in Chinese Holsteins that was mapped to EHHADH by $\mathrm{Li}$ et al. (2014), which is located less than $40 \mathrm{Kbp}$ from the coding region of the gene. Gene EHHADH encodes a multifunctional protein that catalyzes 3 steps of $\beta$-oxidation of fatty acids (Voet et al., 2002). For the analysis of first lactation EBV, a large allele substitution effect (30.6) was estimated for the SNP rs210660950; this finding is most likely heavily influenced by the low frequency of the minor allele (0.0189).
In fact, we found no homozygous calls for the minor allele in the sample of cows that were genotyped.

\section{Limitations and Implications}

In this study, putative SNP within candidate genes related to ketosis were tested to detect associations between a cow's genotype and ketosis resistance in Canadian Holsteins. This study made use of producer-recorded cow health records for selecting animals for genotyping as well as official Canadian genetic evaluations. These existing data sets greatly reduced the labor, time, and costs associated with phenotype collection. However, the available records were limited by the small sample of cows. To improve the chances of capturing more variation in the sample, cows were chosen nonrandomly to increase the proportion of animals that had a case of ketosis at some point in their productive life. The inflated disease frequencies in the sample introduce bias and, therefore, the reported SNP effects resulting from the analyses were most likely overestimated. Another limitation of using a case-control design for selecting animals is the reduced power to detect association for alternate traits, such as milk BHB. Although clinical ketosis and milk BHB are related traits, the genetic correlation is not perfect (0.48-0.75; Koeck et al., 2014, 2015). Table 1 reports the average concentration of milk 
BHB for each subset of cows in the study. Although we noted an elevated disease frequency in the sample of cows, the average concentration of milk BHB was well below the threshold of $0.20 \mathrm{mmol} / \mathrm{L}$ that is indicative of hyperketonemia (Denis-Robichaud et al., 2014). In fact, only $7 \%$ of cows in the first or later lactation subset had a recorded milk BHB concentration of $0.20 \mathrm{mmol} / \mathrm{L}$ or higher. Future plans that include genotyping many more animals with the custom marker panel will allow for better analysis of metabolic traits related to ketosis.

In addition to testing the association of candidate gene SNP with ketosis traits, the results of our study also provide proof of concept for the detection of SNP in silico using bovine cDNA databases. This strategy allowed for the fine-mapping of many key genes without the need to sequence each gene individually and phenotype many cattle, but was also restricted by the quality of sequence data available in online collections. Evidence of this limitation was seen in the high proportion $(66 \%)$ of markers that were not polymorphic. It was expected that several of the SNP included on the custom panel would not be segregating, as sequence data in online databases comes from a variety of sources. The sequence data that was attained for the in silico investigation was submitted by anonymous researchers who study a variety of populations and breeds.

Susceptibility to ketosis likely varies across breeds; van Dorland et al. (2014) described breed differences for the response to metabolic stress in Brown Swiss, Red Holstein, Swiss Fleckvieh, and Holstein-Friesian cows and Tatone et al. (2017) observed a higher risk of ketosis for Holsteins when compared with Jersey cows. Li et al. (2015) performed a genome-wide association study using data on both Chinese and Danish Holstein populations to increase the power to detect QTL for milk fat traits. The QTL segregating in both populations also provide better evidence of causal genes and mutations. Using cows from different populations or even different breeds would be useful to determine if any fixed SNP in our study may be rare variants that do not segregate in the sample of cows used for the current analyses. Further, increasing parity has been repeatedly shown to increase the risk of hyperketonemia in dairy cattle (Duffield et al., 1997; Vanholder et al., 2015; Tatone et al., 2017). Cows in their second or greater lactation have a greater risk of developing ketosis than primiparous cows (odds ratio $=1.5$ for parity 2 and 2.8 for parity 3 to 7; Berge and Vertenten, 2014); however, in the sample of cows used for the current study, we found a higher frequency of disease in the first-parity records than the later parities. This finding could partially explain the stronger associations found for the analysis of first-lactation records compared with later-lactation records.

\section{CONCLUSIONS}

The association analyses used a novel marker panel of SNP that are located within genes involved in the pathogenesis of ketosis to study ketosis resistance. The results revealed 15 SNP with the potential to be used for genetic markers and identified mutations in 6 candidate genes that could lead to a better understanding of metabolic disease susceptibility in dairy cattle. These preliminary results are promising considering the limitations of working with a trait that has low heritability in a small sample of animals. Validation studies should be planned to confirm the findings of our study and to determine the effects of potential rare variants that were not segregating in this sample. Identifying and understanding the genetic factors that predispose cows to ketosis would benefit the dairy industry as a whole by providing producers, breeding services, and veterinarians a tool to forecast a cow's susceptibility to this disease.

\section{ACKNOWLEDGMENTS}

The authors acknowledge the Canadian Dairy Network, Guelph, Ontario, Canada, for providing the data used in this study. This work was funded by grants from the Canadian Dairy Network and the Natural Sciences and Research Council of Canada.

\section{REFERENCES}

Akbar, H., F. Batistel, J. K. Drackley, and J. J. Loor. 2015a. Alterations in hepatic FGF21, co-regulated genes, and upstream metabolic genes in response to nutrition, ketosis and inflammation in peripartal Holstein cows. PLoS One 10:e0139963.

Akbar, H., T. M. Grala, M. Vailati Riboni, F. C. Cardoso, G. Verkerk, J. McGowen, K. Macdonald, J. Webster, K. Schutz, S. Meier, L. Matthews, J. R. Roche, and J. J. Loor. 2015b. Body condition score at calving affects systemic and hepatic transcriptome indicators of inflammation and nutrient metabolism in grazing dairy cows. J. Dairy Sci. 98:1019-1032.

Bauman, D. E., and B. Currie. 1980. Partitioning of nutrients during pregnancy and lactation: A review of mechanisms involving homeostasis and homeorhesis. J. Dairy Sci. 63:1514-1529.

Benjamini, Y., and Y. Hochberg. 1995. Controlling the false discovery rate: A practical and powerful approach to multiple testing. J. R. Stat. Soc. Series B Stat. Methodol. 57:298-300.

Berge, A. C., and G. Vertenten. 2014. A field study to determine the prevalence, dairy herd management systems, and fresh cow clinical conditions associated with ketosis in western European dairy herds. J. Dairy Sci. 97:2145-2154.

Brøndum, R. F., G. Su, L. Janss, G. Sahana, B. Guldbrandtsen, D. Boichard, and M. S. Lund. 2015. Quantitative trait loci markers derived from whole genome sequence data increases the reliability of genomic prediction. J. Dairy Sci. 98:4107-4116.

Buitenhuis, A. J., U. K. Sundekilde, N. A. Poulsen, H. C. Bertram, L. B. Larsen, and P. Sorensen. 2013. Estimation of genetic parameters and detection of quantitative trait loci for metabolites in Danish Holstein milk. J. Dairy Sci. 96:3285-3295.

Chapinal, N., S. J. LeBlanc, M. E. Carson, K. E. Leslie, S. Godden, M. Capel, J. E. P. Santos, M. W. Overton, and T. F. Duffield. 2012. Herd-level association of serum metabolites in the transition 
period with disease, milk production, and early lactation reproductive performance. J. Dairy Sci. 95:5676-5682.

Clempson, A. M., G. E. Pollott, J. S. Brickell, and D. C. Wathes. 2012. Associations between bovine IGFBP2 polymorphisms with fertility, milk production, and metabolic status in UK dairy cows. Anim. Biotechnol. 23:101-113.

Clop, A., F. Marcq, H. Takeda, D. Pirottin, X. Tordoir, B. Bibe, J. Bouix, F. Caiment, J.-M. Elsen, F. Eychenne, C. Larzul, E. Laville, F. Meish, D. Milenkovic, J. Tobin, C. Charllier, and M. Georges. 2006. A mutation creating a potential illegitimate microRNA target site in the myostatin gene affects muscularity in sheep. Nat. Genet. 38:813-818

Denis-Robichaud, J., J. Dubuc, D. Lefebvre, and L. DesCoteaux. 2014. Accuracy of milk ketone bodies from flow-injection analysis for the diagnosis of hyperketonemia in dairy cows. J. Dairy Sci. 97:3364-3370.

Drackley, J. K., H. M. Dann, G. N. Douglas, N. A. Janovik Guretzky, N. B. Litherland, J. P. Underwood, and J. J. Loor. 2005. Physiological and pathological adaptations in dairy cows that may increase susceptibility to periparturient diseases and disorders. Ital. J. Anim. Sci. 4:323-344.

Duffield, T. F., D. F. Kelton, K. E. Leslie, K. D. Lissemore, and J. H. Lumsden. 1997. Use of test day milk fat and milk protein to detect subclinical ketosis in dairy cattle in Ontario. Can. Vet. J. 38:713-718.

Garrick, D. J., J. F. Taylor, and R. I. Fernando. 2009. Deregressing estimated breeding values and weighting information for genomic regression analyses. Genet. Sel. Evol. 41:55.

Graber, M., S. Kohler, T. Kaufmann, M. G. Doherr, R. M. Bruckmaier, and H. A. van Dorland. 2010. A field study on characteristics and diversity of gene expression in the liver of dairy cows during the transition period. J. Dairy Sci. 93:5200-5215.

Heitmann, R. N., D. J. Dawes, and S. C. Sensenig. 1987. Hepatic ketogenesis and peripheral ketone body utilization in the ruminant. J. Nutr. 117:1174-1180.

Herdt, T. H. 2000. Ruminant adaptation to negative energy balance: Influences on the etiology of ketosis and fatty liver. Vet. Clin. North Am. Food Anim. Pract. 16:215-230.

Jamrozik, J., G. J. Kistemaker, B. J. Van Doormaal, A. Fleming, A. Koeck, and F. Miglior. 2016b. Genetic evaluation for resistance to metabolic diseases in Canadian dairy breeds. Interbull Bull. 50:9-16.

Jamrozik, J., A. Koeck, G. J. Kistemaker, and F. Miglior. 2016a. Multiple-trait estimates of genetic parameters for metabolic disease traits, fertility disorders, and their predictors in Canadian Holsteins. J. Dairy Sci. 99:1990-1998.

Kargo, M., L. Hjorto, M. Toivonen, J. A. Eriksson, G. P. Aamand, and J. Pederson. 2014. Economic basis for the Nordic Total Merit Index. J. Dairy Sci. 97:7879-7888.

Koeck, A., J. Jamrozik, G. J. Kistemaker, F. S. Schenkel, R. K. Moore, D. M. Lefebvre, D. F. Kelton, and F. Miglior. 2015. Development of genetic evaluations for metabolic disease traits for Canadian Dairy Cattle. Interbull Bull. 49:76-79.

Koeck, A., J. Jamrozik, F. S. Schenkel, R. K. Moore, D. M. Lefebvre, D. F. Kelton, and F. Miglior. 2014. Genetic analysis of milk $\beta$-hydroxybutyrate and its association with fat-to-protein ratio, body condition score, clinical ketosis, and displaced abomasum in early first lactation of Canadian Holsteins. J. Dairy Sci. 97:72867292.

Koeck, A., F. Miglior, D. F. Kelton, and F. S. Schenkel. 2012. Health recording in Canadian Holsteins: Data and genetic parameters. J. Dairy Sci. 95:4099-4108.

Li, C., D. Sun, S. Zhang, S. Wang, X. Wu, Q. Zhang, L. Liu, Y. Li, and L. Qiao. 2014. Genome wide association study identified 20 novel promising genes associated with milk fatty acid traits in Chinese Holstein. PLoS One 9:e96186. https://doi.org/10.1371/ journal.pone.0096186.

Li, P., X. B. Li, S. X. Fu, C. C. Wu, X. X. Wang, G. J. Yu, M. Long, Z. Wang, and G. W. Lui. 2012. Alterations of fatty acid $\beta$-oxidation capability in the liver of ketotic cows. J. Dairy Sci. 95:1759-1766.
Li, X., A. J. Buitenhuis, M. S. Lund, C. Li, D. Sun, Q. Zhang, N. A. Poulsen, and G. Su. 2015. Joint genome-wide association study for milk fatty acid traits in Chinese and Danish Holstein populations. J. Dairy Sci. 98:8152-8163.

Loor, J. J., H. M. Dann, R. E. Everts, R. Oliveira, C. A. Green, N. A. Janovick Guretzky, S. L. Rodriguez-Zas, H. A. Lewin, and J. K. Drackley. 2005. Temporal gene expression profiling of liver from periparturient dairy cows reveals complex adaptive mechanisms in hepatic function. Physiol. Genomics 23:217-226.

Loor, J. J., R. E. Everts, M. Bionaz, H. M. Dann, D. E. Morin, R. Oliveira, S. L. Rodriguez-Zas, J. K. Drackley, and H. A. Lewin. 2007. Nutrition-induced ketosis alters metabolic and signaling gene networks in liver of periparturient dairy cows. Physiol. Genomics 32:105-116.

Menashe, I., P. S. Rosenberg, and B. E. Chen. 2008. PGA: Power calculator for case-control genetic association analyses. BMC Genet. 9:36.

Miglior, F., R. Finocchiaro, F. Malchiodi, A. Fleming, L. Brito, C F. Baes, J. Jamrozik, P. Martin, J. Chesnais, and F. S. Schenkel. 2017. Enhancing the data pipeline for novel traits in the genomic era: from farms to DHI to evaluation centres. ICAR Tech. Ser. 21:23-30.

Miglior, F., B. L. Muir, and B. J. Van Doormaal. 2005. Selection indices in Holstein cattle of various countries. J. Dairy Sci. 88:12551263.

Moyes, K. M., E. Bendixen, M. C. Codrea, and K. L. Ingvarsten. 2013. Identification of hepatic biomarkers for physiological imbalance of dairy cows in early and mid lactation using proteomic technology. J. Dairy Sci. 96:3599-3610.

Neuenschwander, T. F.-O., F. Miglior, J. Jamrozik, O. Berke, D. F. Kelton, and L. R. Schaeffer. 2012. Genetic parameters for producer-recorded health data in Canadian Holstein cattle. Animal 6:571-578.

Parker Gaddis, K. L., J. B. Cole, J. S. Clay, and C. Maltecca. 2014 Genomic selection for producer-recorded health event data in US dairy cattle. J. Dairy Sci. 97:3190-3199.

Raven, L.-A., B. G. Cocks, K. E. Kemper, A. J. Chamberlain, C. J. Vander Jagt, M. E. Goddard, and B. J. Hayes. 2016. Targeted imputation of sequence variants and gene expression profiling identifies twelve candidate genes associated with lactation volume, composition and calving internal in dairy cattle. Mamm. Genome 27:81-97.

Reynolds, C. K., P. C. Aikman, B. Lupoli, D. J. Humphries, and D. E. Beever. 2003. Splanchic metabolism of dairy cows during the transition from late gestation through early lactation. J. Dairy Sci 86:1201-1217.

Sargolzaei, M. 2014. SNP1101 User's Guide. Version 1.0. HiggsGene Solutions Inc., Guelph, Ontario, Canada.

Schäff, C., S. Börner, S. Hacke, U. Katuzsch, H. Sauerwein, S. K. Spachmann, M. Schweigel-Röntgen, H. M. Hammon, and B. Kuhla. 2013. Increased muscle fatty acid oxidation in dairy cows with intensive body fat mobilization during early lactation. J. Dairy Sci. 96:6449-6460.

Sim, N.-L., P. Kumar, J. Hu, S. Henikoff, G. Schneider, and P. C. Ng. 2012. SIFT web server: Predicting effects of amino acid substitutions on proteins. Nucleic Acids Res. 40:W452-7.

Tamminga, S., P. A. Luteijn, and R. G. M. Meijer. 1997. Changes in composition and energy content of liveweight loss in dairy cows with time after parturition. Livest. Prod. Sci. 52:31-38.

Tatone, E. H., T. F. Duffield, S. J. LeBlanc, T. J. DeVries, and J. L. Gordon. 2017. Investigating the within-herd prevalence and risk factors for ketosis in dairy cattle in Ontario as diagnosed by the test-day concentration of $\beta$-hydroxybutyrate in milk. J. Dairy Sci. 100:1308-1318.

Tetens, J., T. Seidenspinner, N. Buttchereit, and G. Thaller. 2013 Whole-genome association study for energy balance and fat/protein ratio in German Holstein bull dams. Anim. Genet. 44:1-8.

van der Drift, S. G. A., K. J. E. van Hulzen, T. G. Teweldemedhn, R. Jorritsma, M. Nielen, and H. C. M. Heuven. 2012. Genetic and nongenetic variation in plasma and milk $\beta$-hydroxybutyrate and 
milk acetone concentrations of early-lactation dairy cows. J. Dairy Sci. 95:6781-6787.

van Dorland, H. A., M. Graber, S. Kohler, A. Steiner, and R. M. Bruckmaier. 2014. Comparison of hepatic adaptation in extreme metabolic phenotypes observed in early lactation dairy cows onfarm. J. Anim. Physiol. Anim. Nutr. (Berl.) 98:693-703.

van Dorland, H. A., S. Richter, L. Morel, M. G. Doherr, N. Castro, and R. M. Bruckmaier. 2009. Variation in hepatic regulation of metabolism during the dry period and in early lactation in dairy cows. J. Dairy Sci. 92:1924-1940.

Vanholder, T., J. Papen, R. Bemers, G. Vertenten, and A. C. B. Berge 2015. Risk factors for subclinical and clinical ketosis and association with production parameters in dairy cows in the Netherlands. J. Dairy Sci. 98:880-888.

VanRaden, P. M., J. R. O'Connell, G. R. Wiggens, and K. A. Weigel. 2011. Genomic evaluations with many more genotypes. Genet. Sel. Evol. 43:10.

Voet, D., J. G. Voet, and C. W. Pratt. 2002. Fundamentals of Biochemistry. Rev. ed. John Wiley \& Sons Inc., New York, NY.
Vukasinovic, N., N. Bacciu, C. A. Przybyla, P. Boddhireddy, and S. K. DeNise. 2017. Development of genetic and genomic evaluation for wellness traits in US Holstein cows. J. Dairy Sci. 100:428-438.

Weber, C., C. Hametner, A. Tuchscherer, B. Losand, E. Kantiz, W. Otten, H. Sauerwein, R. M. Bruckmaier, F. Becker, W. Kanitz, and H. M. Hammon. 2013. Hepatic gene expression involved in glucose and lipid metabolism in transition cows: Effects of fat mobilization during early lactation in relation to milk performance and metabolic changes. J. Dairy Sci. 96:5670-5681.

White, H. M., S. L. Koser, and S. S. Donkin. 2011. Characterization of bovine pyruvate carboxylase promoter 1 responsiveness to serum from control and feed-restricted cows. J. Anim. Sci. 89:1763-1768. Zwald, N. R., K. A. Weigel, Y. M. Chang, R. D. Welper, and J. S. Clay. 2004. Genetic selection for health traits using producerrecorded data. I. Incidence rates, heritability estimates, and sire breeding values. J. Dairy Sci. 87:4287-4294. 